\title{
[12] $\mathrm{aneN}_{3}$ Modified Tetraphenylethene Molecules as High-Performance Sensing, Condensing, and Delivering Agents toward DNAs
}

Ai-Xiang Ding, Quan Tang, Yong-Guang Gao, You-Di Shi, Alam Uzair, and Zhong-Lin Lu*

Key Laboratory of Theoretical and Computational Photochemistry, Ministry of Education; College of Chemistry, Beijing Normal University, Beijing 100875, China

*Corresponding authors: luzl@bnu.edu.cn.

\section{Content}

1. The sequences of the synthetic oligonucleotides (Table S1).... .2

2. Figures for AIE measurements (Figure S1, Figure S2)..... $2-3$

3. DLS measurements (Figure S3). .3

4. Fluorescence titrations with DNAs (Figure S4 S10, Table S2). 3-6

5. Condensing behaviors of previously reported [12] $\mathrm{aneN}_{3}$ derivatives with DNA (Table S3).....7

6. Figures for condensing natures (Figure S11 S13, Table S4). 8-9

7. Cellular uptake studies at $0.5 \mathrm{~h}$ (Figure S14)

8. IR spectra of compounds 1-4 (Figure S15).

9. ${ }^{1} \mathrm{H},{ }^{13} \mathrm{C}-\mathrm{NMR}$ Spectra and HR-MS of compounds 1-4 (Figure S16 S27) $9-15$

10. References 16 


\section{The sequences of the synthetic oligonucleotides}

Table S1. The sequences of the synthetic oligonucleotides used in our study.

\begin{tabular}{ll}
\hline ID & Sequence \\
\hline X10 & 5'-GGTGCTAACT-3' \\
Y10 & 5'-AGTTAGCACC-3' \\
X20 & 5'-GGTGCTAACTGGTGCTAACT-3' \\
Y20 & 5'-AGTTAGCACCAGTTAGCACC-3' \\
X30 & 5'-GGTGCTAACTGGTGCTAACTGGTGCTAACT-3' \\
Y30 & 5'-AGTTAGCACCAGTTAGCACCAGTTAGCACC-3' \\
\hline
\end{tabular}

\section{Figures for AIE natures:}
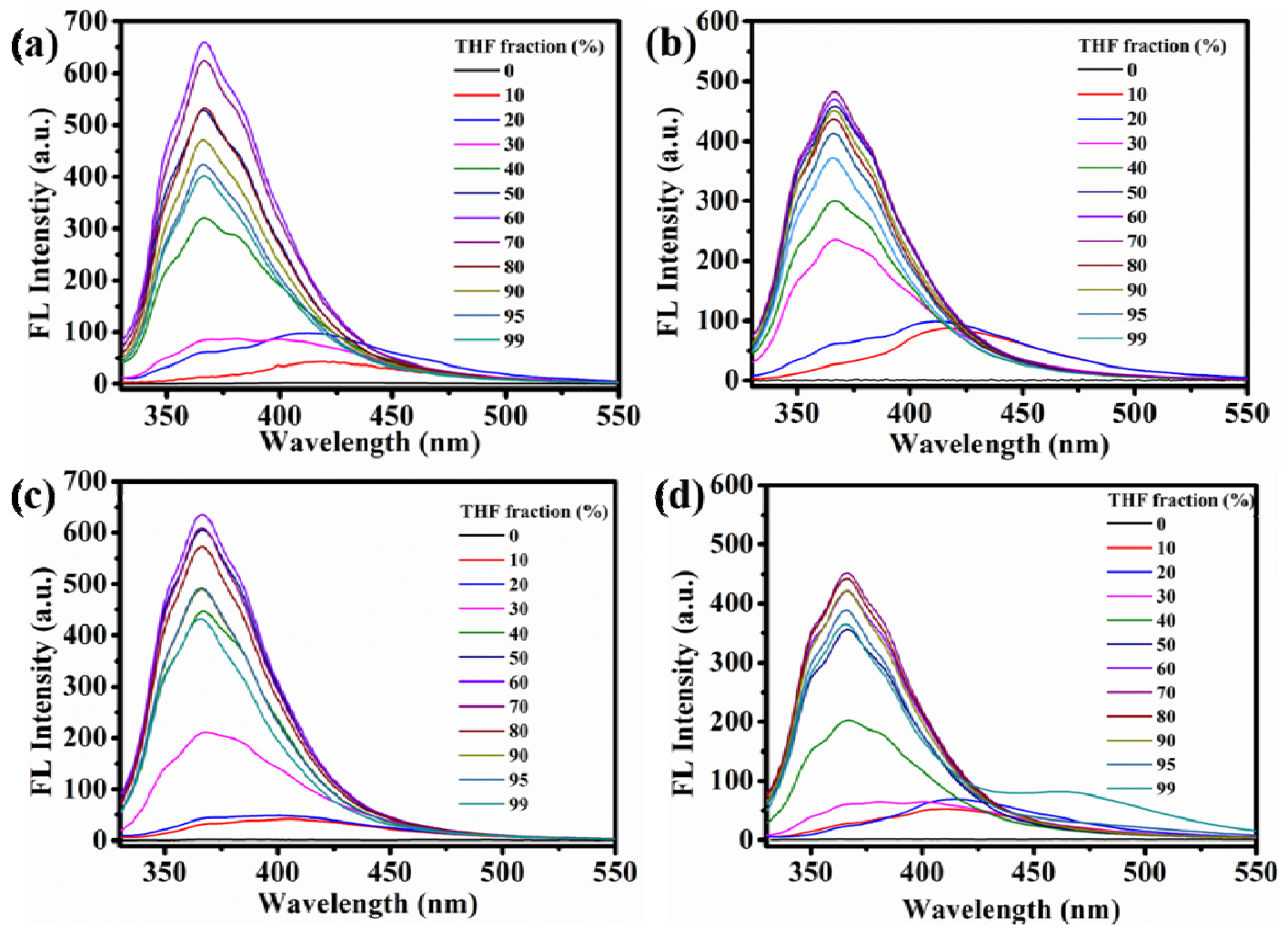

Figure S-1. PL spectra of 1 (a), 2 (b), 3 (c), and 4 (d) in water/THF mixtures with different THF fraction, $[$ Dyes $]=10 \mu \mathrm{M}, \lambda_{\mathrm{ex}}=320 \mathrm{~nm}$.

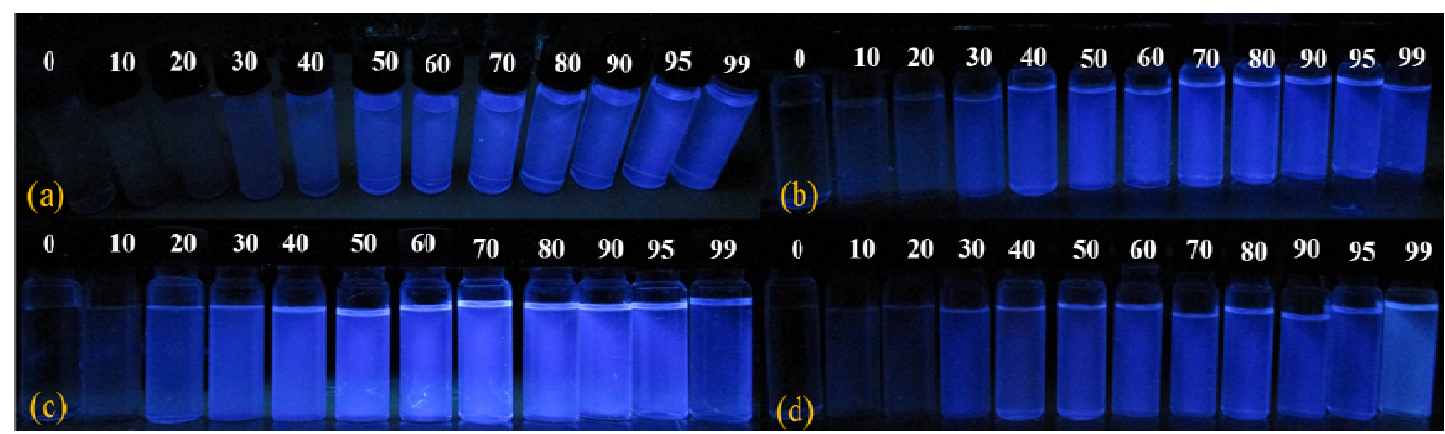

Figure S-2. Photographs of 1 (a), 2 (b), 3 (c) and 4 (d) recorded under UV $365 \mathrm{~nm}$ light in water/THF mixtures with increasing THF fraction (\%). 


\section{DLS measurements}
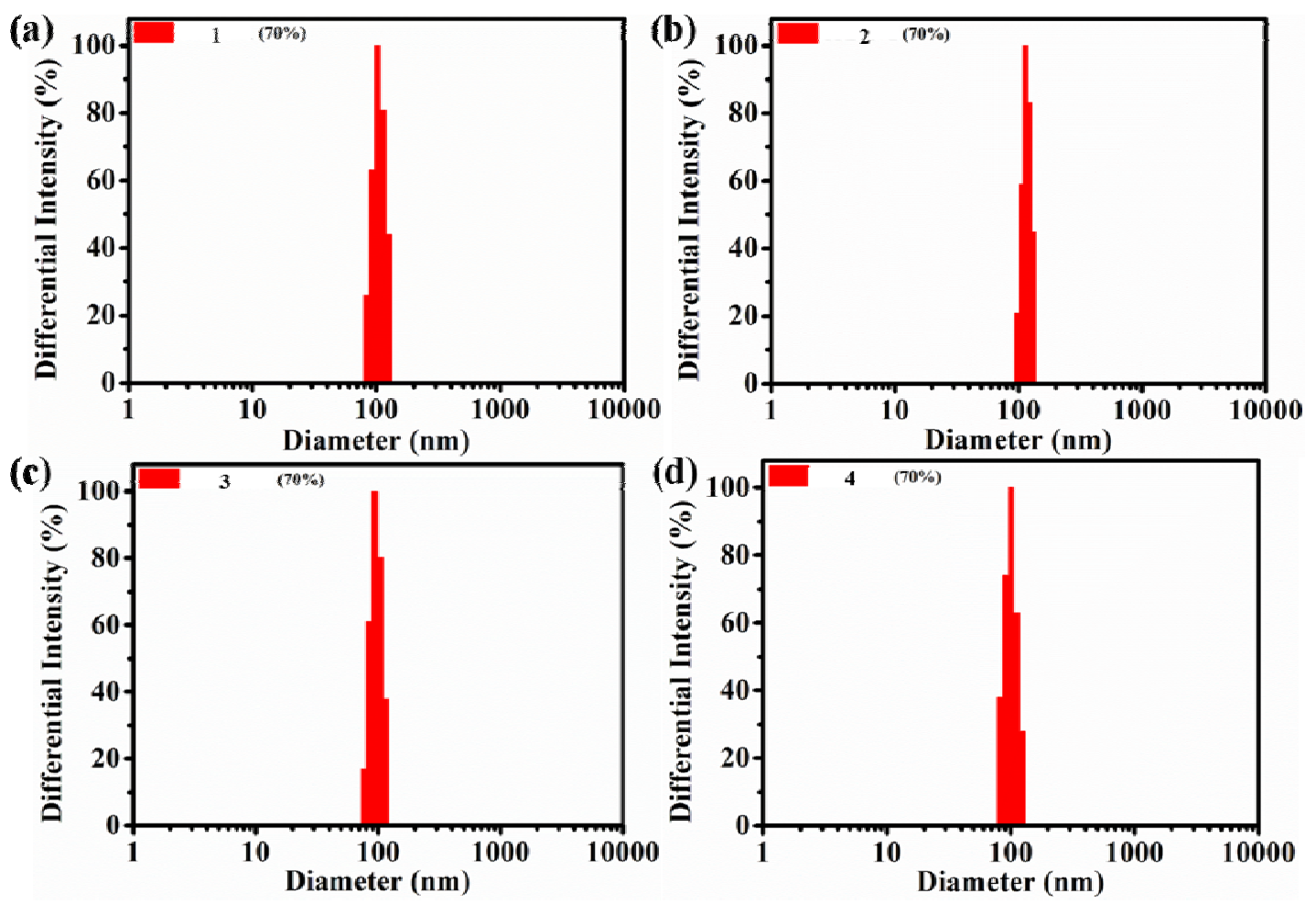

Figure S-3. Particle size distributions of 1 (a), 2 (b), 3 (c) and 4 (d) in water/THF mixtures with THF volume fraction $=70 \%$.

\section{Fluorescence titrations with DNAs:}
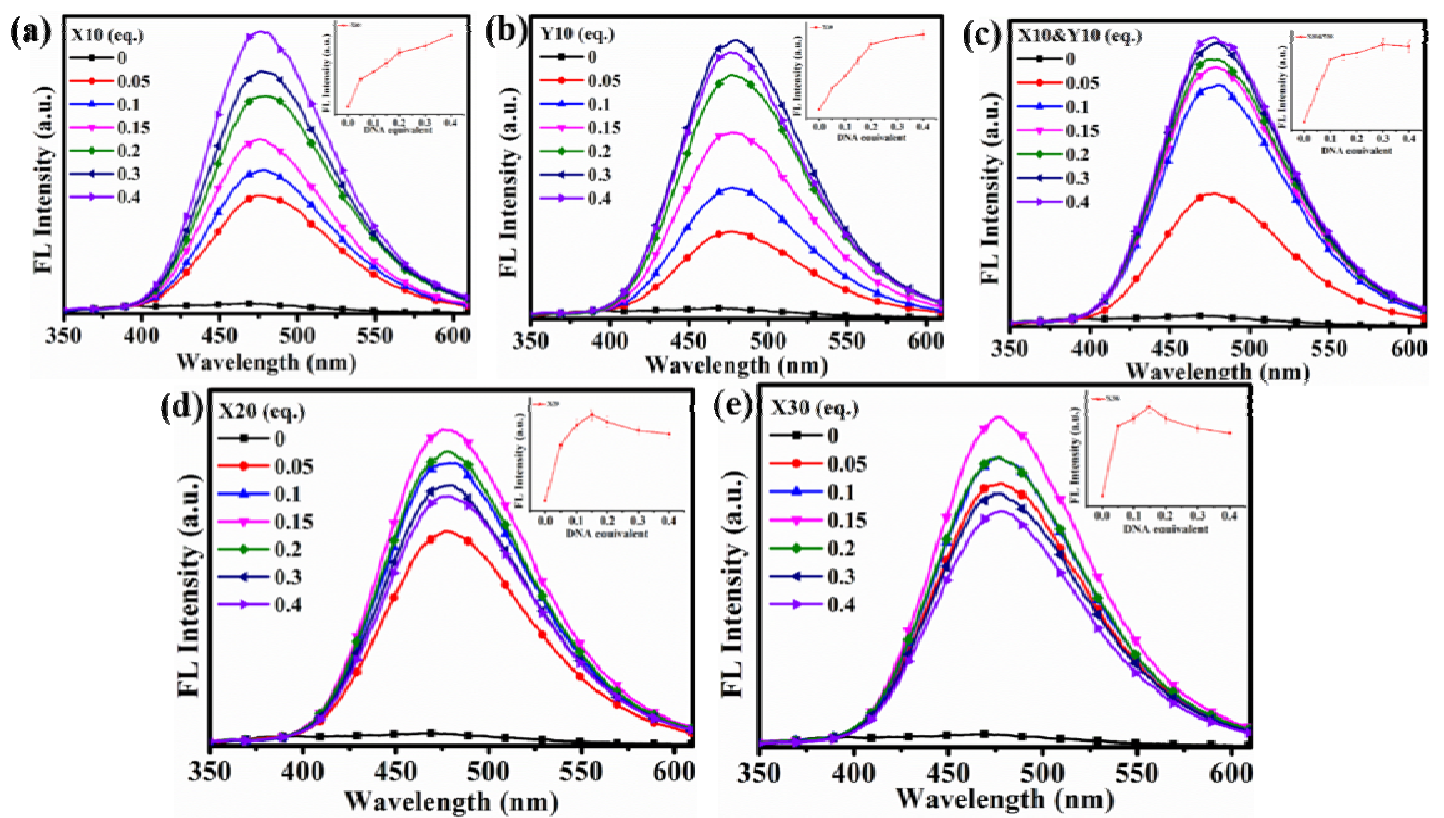

Figure S-4. Fluorescence titrations of different ssDNAs (X10, a; Y10, b; X20, d; X30, e) and a dsDNA $(\mathrm{X} 10 \& \mathrm{Y} 10, \mathrm{c})$ to 2 in Tris-HCl buffer $(\mathrm{pH}=7.4),[\mathrm{Dyes}]=10 \mu \mathrm{M}, \lambda_{\mathrm{ex}}=320 \mathrm{~nm}$. Error bars are $\pm \mathrm{SD}$. 

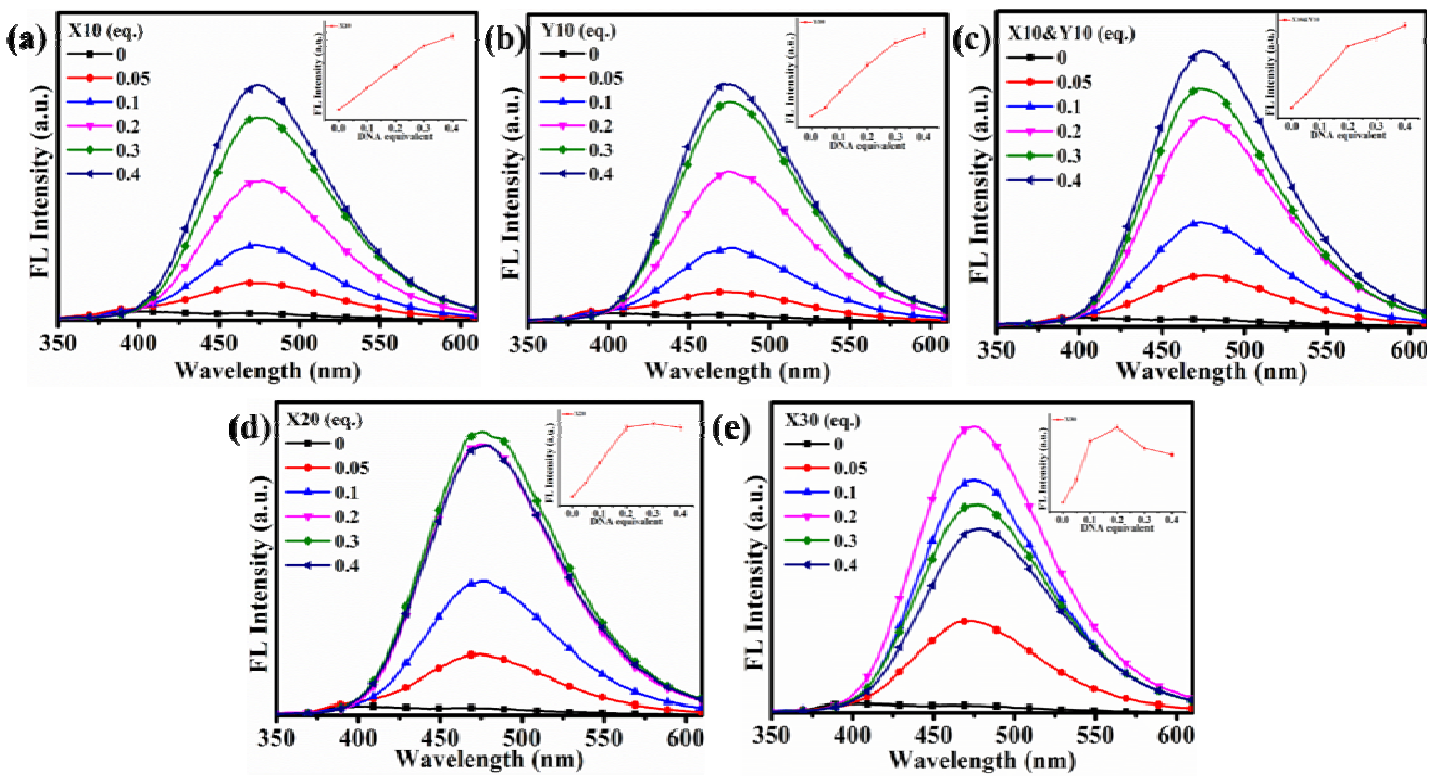

Figure S-5. Fluorescence titrations of different ssDNAs (X10, a; Y10, b; X20, d; X30, e) and a dsDNA $(\mathrm{X} 10 \& \mathrm{Y} 10, \mathrm{c})$ to 4 in Tris-HCl buffer $(\mathrm{pH}=7.4)$, insets: Plots of PL peak intensity vs DNA equivalents, $[$ Dyes $]=10 \mu \mathrm{M}, \lambda_{\mathrm{ex}}=320 \mathrm{~nm}, \lambda_{\mathrm{em}}=479 \mathrm{~nm}$. Error bars are $\pm \mathrm{SD}$.
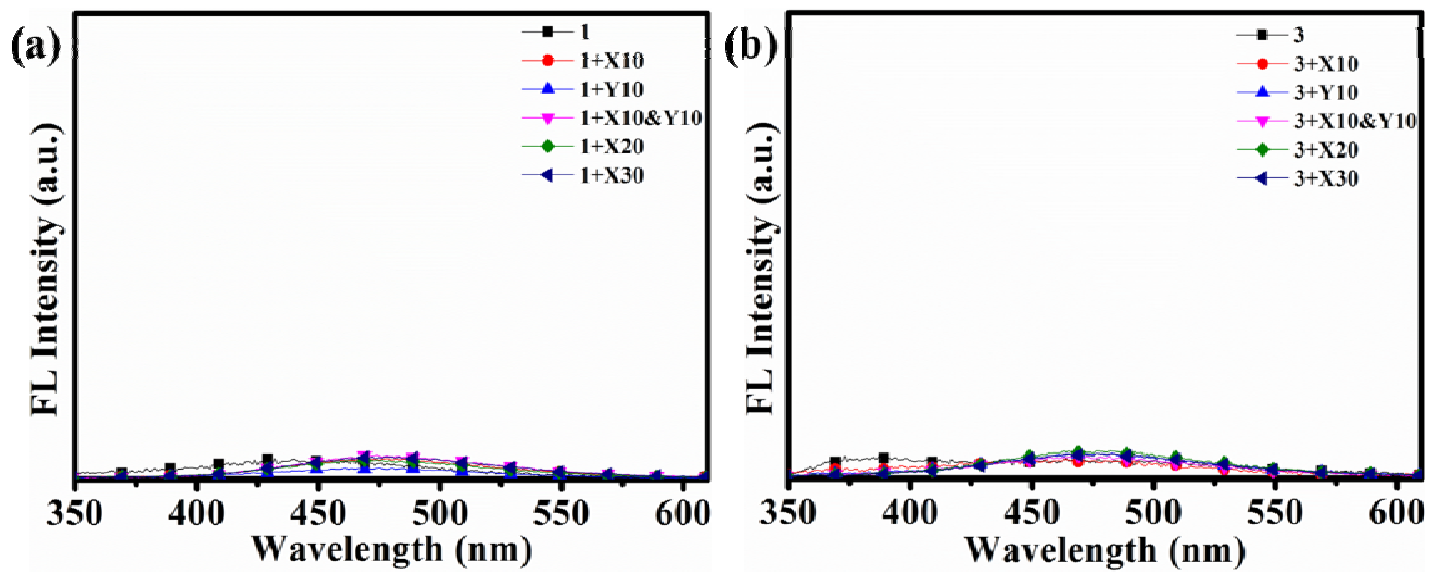

Figure S-6. Fluorescent spectra of $\mathbf{1}$ (a) and $\mathbf{3}$ (b) upon addition of 0.5 equivalent DNAs in Tric-HCl buffer $(\mathrm{pH}=7.4)$, [Dyes] $=10 \mu \mathrm{M}, \lambda_{\mathrm{ex}}=320 \mathrm{~nm}$.
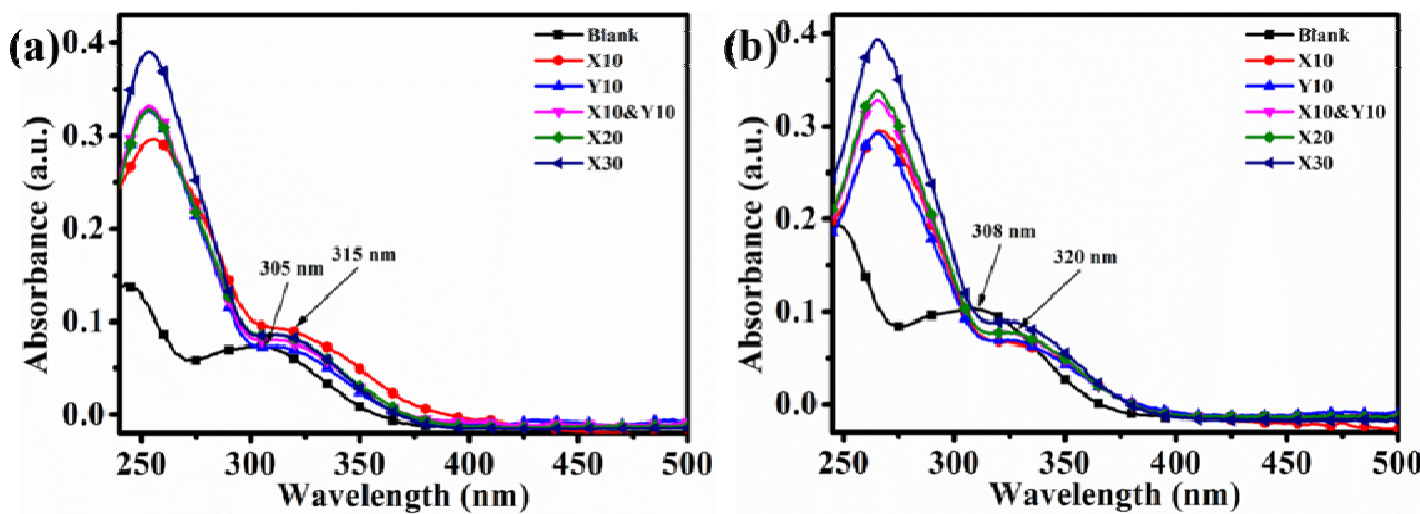

Figure S-7. The UV-vis spectra of 1 (a) and 3 (b) after addition of 0.1 equivalent DNAs in Tris-HCl buffer $(\mathrm{pH}=7.4),[$ Dyes $]=10 \mu \mathrm{M}$. 
Table S-2. Emission enhancement calculated from the fluorescent titration of DNAs.

\begin{tabular}{lllllllllll}
\hline DNA eq. & \multicolumn{3}{c}{ Compound 2 } \\
\hline & X10 & Y10 & X10\&Y10 & X20 & X30 & X10 & Y10 & X10\&Y10 & X20 & X30 \\
0.05 & 9.3 & 8.1 & 12.2 & 16.8 & 20.5 & 5.3 & 4.5 & 7.1 & 9.1 & 14.0 \\
0.1 & 13.7 & 12.3 & 21.3 & 22.4 & 24.0 & 10.6 & 10.5 & 14.3 & 18.8 & 32.6 \\
0.2 & 20.6 & 22.8 & 24.6 & 23.3 & 22.5 & 19.7 & 21.0 & 28.8 & 37.4 & 42.0 \\
0.3 & 23.0 & 25.0 & 27.6 & 20.7 & 19.7 & 28.8 & 30.0 & 32.6 & 39.1 & 29.0 \\
0.4 & 26.7 & 26.1 & 26.9 & 19.8 & 18.4 & 33.1 & 33.6 & 37.8 & 37.1 & 25.7 \\
\hline
\end{tabular}
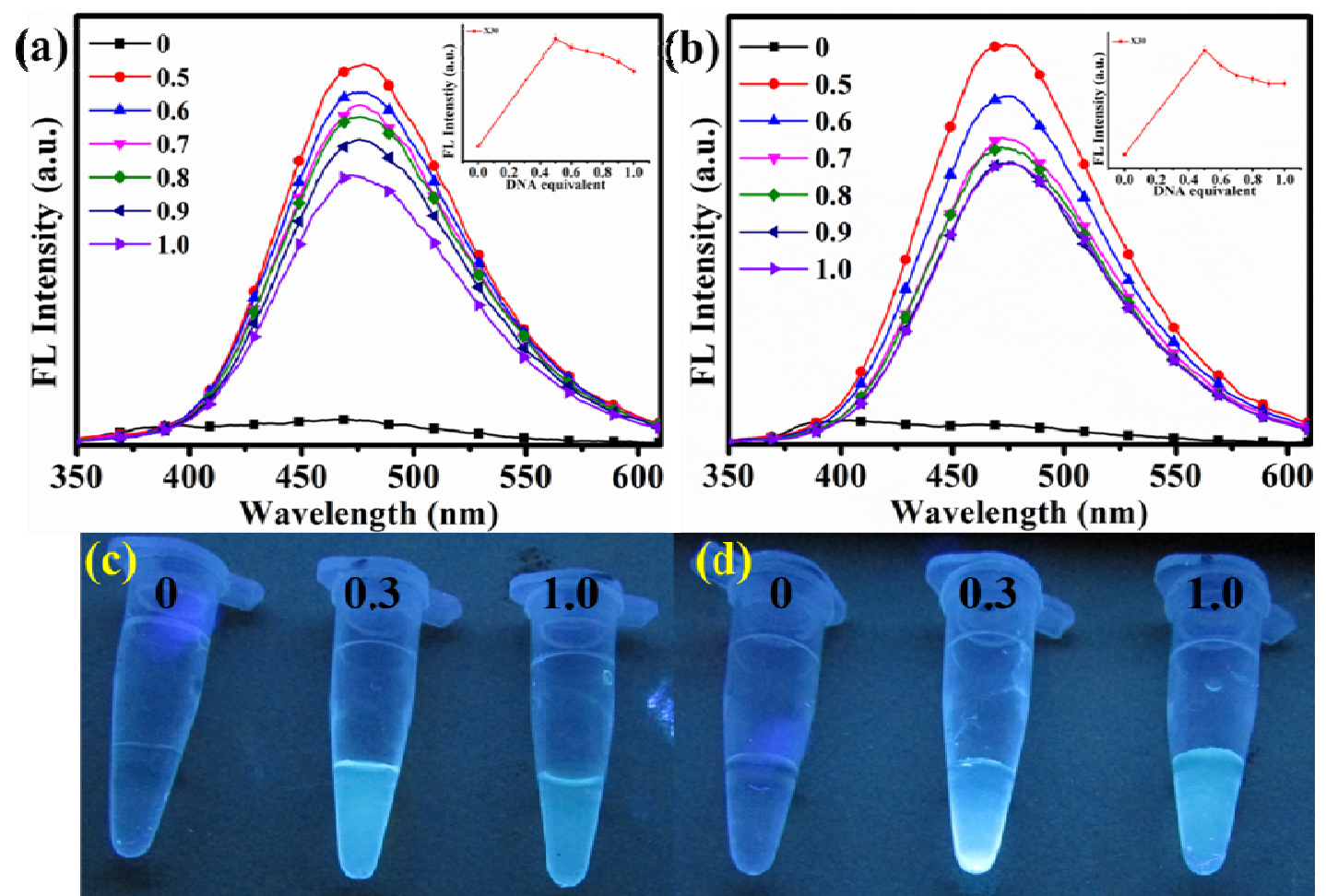

Figure S-8. (a) 2 and (b) 4: fluorescence titrations of X30 in Tris- $\mathrm{HCl}$ buffer ( $\mathrm{pH}=7.4$ ), insets: Plots of PL peak intensity vs DNA equivalents, (c) 2 and (d) 4 photographs recorded under a UV $365 \mathrm{~nm}$ lamp with addition of $0,0.3$ and 1.0 equivalent $\mathrm{X} 30$ from left to right. [Dyes] $=10 \mu \mathrm{M}, \lambda_{\mathrm{ex}}=320 \mathrm{~nm}, \lambda_{\mathrm{em}}=479 \mathrm{~nm}$. Error bars are \pm SD. 

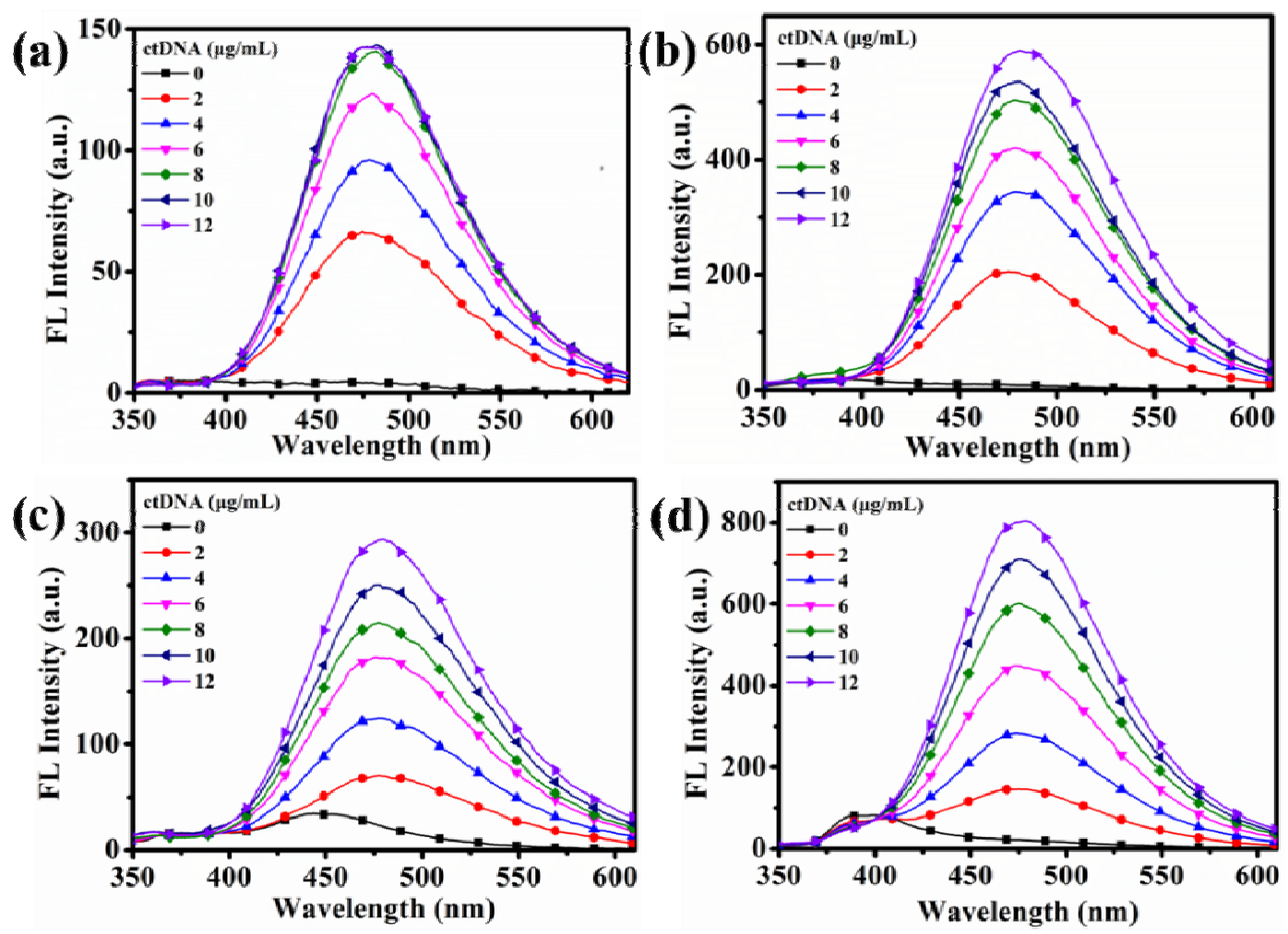

Figure S-9. Fluorescence titration of ctDNA to $10 \mu \mathrm{M} \mathbf{1}$ (a), $\mathbf{2}$ (b), 3 (c) and $\mathbf{4}$ (d) in Tris- $\mathrm{HCl}$ (pH = 7.4) buffer. [Dyes] $=10 \mu \mathrm{M} ; \lambda_{\mathrm{ex}}=320 \mathrm{~nm}, \lambda_{\mathrm{em}}=479 \mathrm{~nm}$.
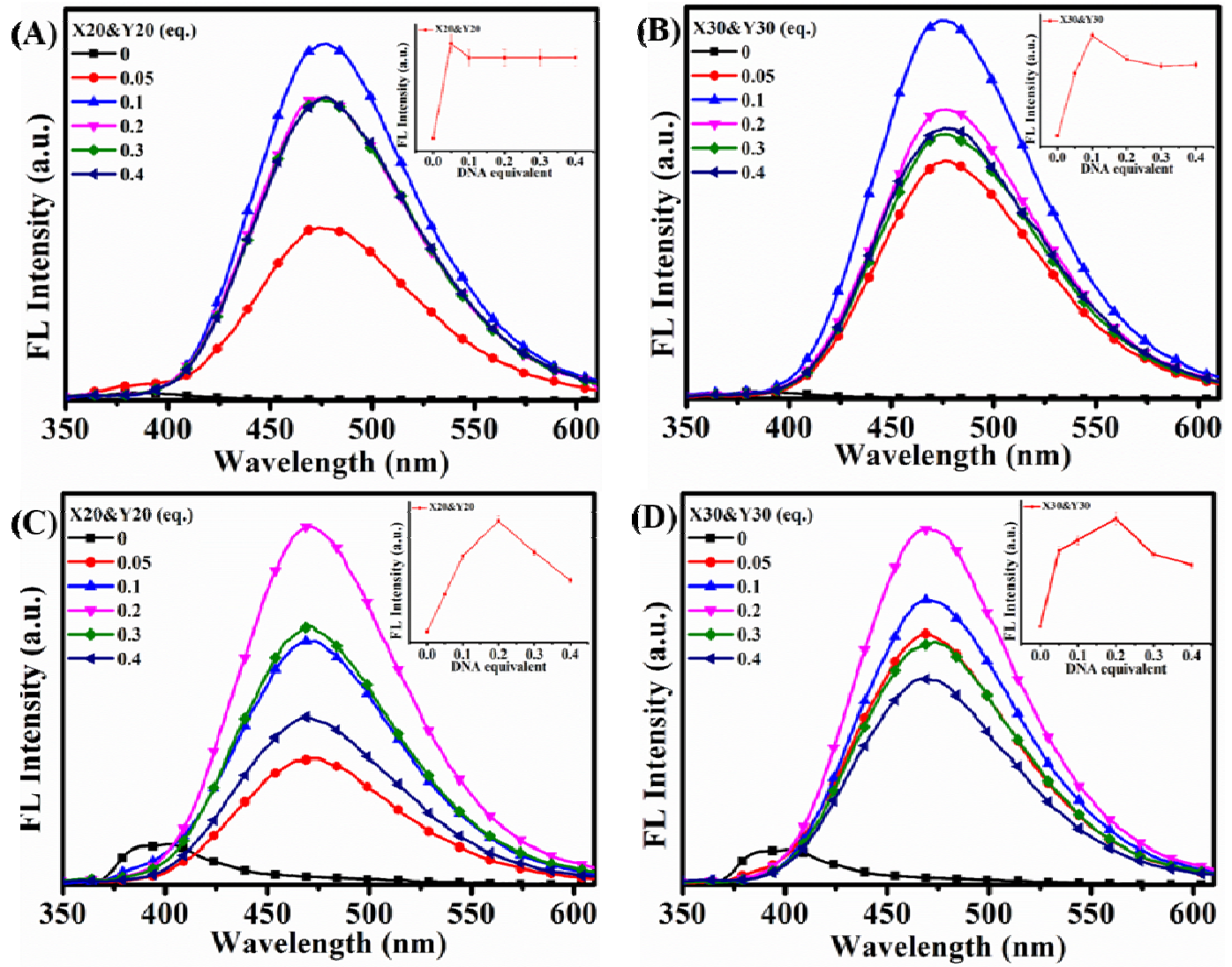

Figure S-10. Fluorescence titration of dsDNAs with different lengths to $10 \mu \mathrm{M} 2$ (A and B), 4 (C and D), in Tris- $\mathrm{HCl}(\mathrm{pH}=7.4)$ buffer. [Dyes] $=10 \mu \mathrm{M} ; \lambda_{\mathrm{ex}}=320 \mathrm{~nm}, \lambda_{\mathrm{em}}=479 \mathrm{~nm}$. 


\section{Condensing behaviors of previously reported [12] $\mathrm{aneN}_{3}$ derivatives}

Table S-3. Condensing behaviors of previously reported [12] $\mathrm{aneN}_{3}$ derivatives with DNA.

\begin{tabular}{|c|c|c|c|c|}
\hline $\begin{array}{l}\text { S. } \\
\text { No. }\end{array}$ & Chemical structure & Completely retardant conc. $(\mu \mathrm{M})$ & $K_{\text {app }}\left(\mathrm{M}^{-1}\right)$ & Reference \\
\hline 1 & & About 120 & $(1.2 \pm 0.1) \times 10^{5}$ & 1 \\
\hline 2 & & Slight lower than 120 & $(0.98 \pm 0.06) \times 10^{5}$ & 1 \\
\hline 3 & & 120 & $2.5 \times 10^{5}$ & 2 \\
\hline 4 & & 80 & $5.0 \times 10^{5}$ & 2 \\
\hline 5 & & N.D. & N.D. & 3 \\
\hline 6 & & above 300 & $(6.4 \pm 0.3) \times 10^{4}$ & 3 \\
\hline 7 & & 80 & $(2.0 \pm 0.1) \times 10^{5}$ & 3 \\
\hline 8 & & $\begin{array}{l}\text { 4a: N.D. } \\
\text { 4b: } 80\end{array}$ & $\begin{array}{l}4 \mathrm{a}:(1.2 \pm 0.1) \times 10^{5} \\
4 \mathrm{~b}:(1.4 \pm 0.1) \times 10^{5}\end{array}$ & 3 \\
\hline 9 & & $\begin{array}{l}\text { 5a: N.D. } \\
\text { 5b: } 40\end{array}$ & $\begin{array}{l}5 \mathrm{a}:(1.36 \pm 0.09) \times 10^{5} \\
5 \mathrm{~b}:(2.4 \pm 0.1) \times 10^{5}\end{array}$ & 3 \\
\hline 10 & & 60 & $(1.8 \pm 0.1) \times 10^{5}$ & 3 \\
\hline 11 & & 10 & N.D. & 4 \\
\hline
\end{tabular}




\section{Figures for condensing natures:}

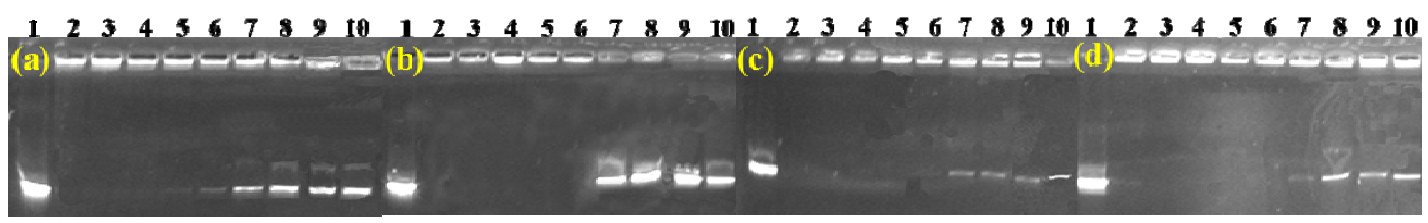

Figure S-11. AGE assay to investigate the effect of ionic strength on pUC18 DNA condensation induced by compounds 1-4, incubation time: $30 \mathrm{~min}$ in $50 \mathrm{mM}$ Tris- $\mathrm{HCl}$ buffer at $37^{\circ} \mathrm{C}$. [DNA] $=9 \mu \mathrm{g} / \mathrm{mL}$, Lane 1 : DNA control, lanes 2-10: $[\mathrm{NaCl}]=0,10,50,100,200,300,400,500,600 \mathrm{mM} ;[1]=25 \mu \mathrm{M}$ (a), [2] $=10 \mu \mathrm{M}$ (b), [3] $=10 \mu \mathrm{M}$ (c), [4] = 5 $\mu \mathrm{M}$ (d).
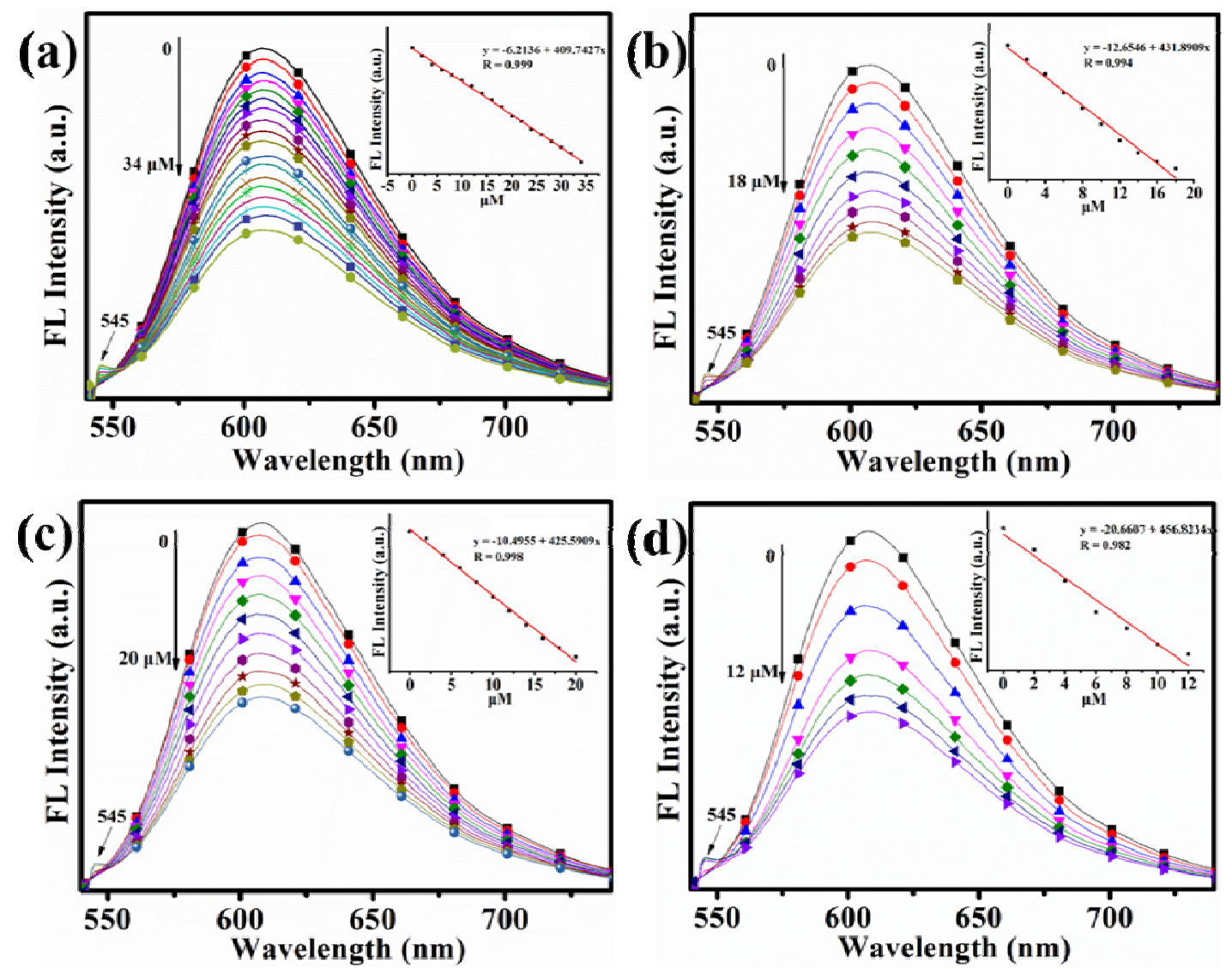

Figure S-12. Fluorescence quenching curves of EB-bounded ctDNA by $\mathbf{1}$ (a), 2 (b), 3 (c) and $\mathbf{4}$ (d) in $5 \mathrm{mM}$ Tris- $\mathrm{HCl} / 50 \mathrm{mM} \mathrm{NaCl}\left(\mathrm{pH} 7.4, \lambda_{\mathrm{ex}}=537 \mathrm{~nm},[\mathrm{~EB}]=20 \mu \mathrm{M},[\mathrm{DNA}]=100 \mu \mathrm{M}, 25.0^{\circ} \mathrm{C}\right)$. The arrows show the intensity changes on increasing the concentration of the agents.

Table S-4. Linearly fitting functions and corresponding data deduced from the plots of $1-I / I_{0}$.

\begin{tabular}{lllll}
\hline & function & $\mathrm{R}$ & $\mathrm{S} . \mathrm{D}$. & $\mathrm{X}_{\mathrm{Y}=0.5}$ \\
\hline TPECN-1 & $\mathrm{Y}=0.0297+0.01512 * \mathrm{X}$ & 0.9990 & 0.00289 & 32.8724 \\
TPECN-2 & $\mathrm{Y}=0.0120+0.02882 * \mathrm{X}$ & 0.9944 & 0.01089 & 16.9330 \\
TPECN-2-2 & $\mathrm{Y}=-0.0128+0.01512 * \mathrm{X}$ & 0.9969 & 0.00746 & 20.8384 \\
TPECN-4 & $\mathrm{Y}=0.0297+0.01512 * \mathrm{X}$ & 0.9822 & 0.02480 & 10.8096 \\
\hline
\end{tabular}




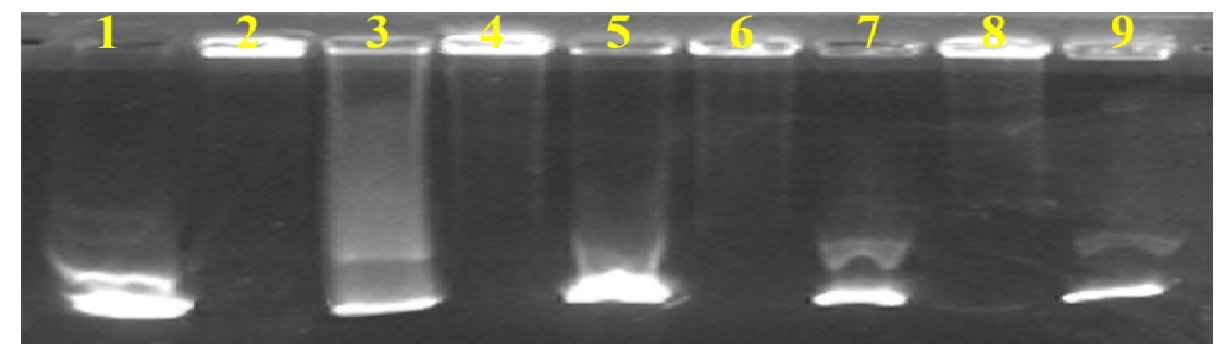

Figure S-13. AGE assay to investigate the reversibility of DNA condensation induced by $\mathbf{1}(25 \mu \mathrm{M}), \mathbf{2}(10$ $\mu \mathrm{M}), 3(10 \mu \mathrm{M})$ and $4(5 \mu \mathrm{M})$ in Tris- $\mathrm{HCl}$ buffer $(50 \mathrm{mM}, \mathrm{pH} 7.4)$ at $37^{\circ} \mathrm{C}$. [DNA] $=9 \mu \mathrm{g} / \mathrm{mL}$, Lane 1: DNA control, lanes 2, 4, 6 and 8: $[\mathrm{NaCl}]=0$, lanes 3, 5, 7 and 9: $[\mathrm{NaCl}]=800 \mathrm{mM}$.

\section{Cellular uptake studies at $0.5 \mathrm{~h}$ :}

BF image

DAPI imuge

BF + DAPI imane

(A)

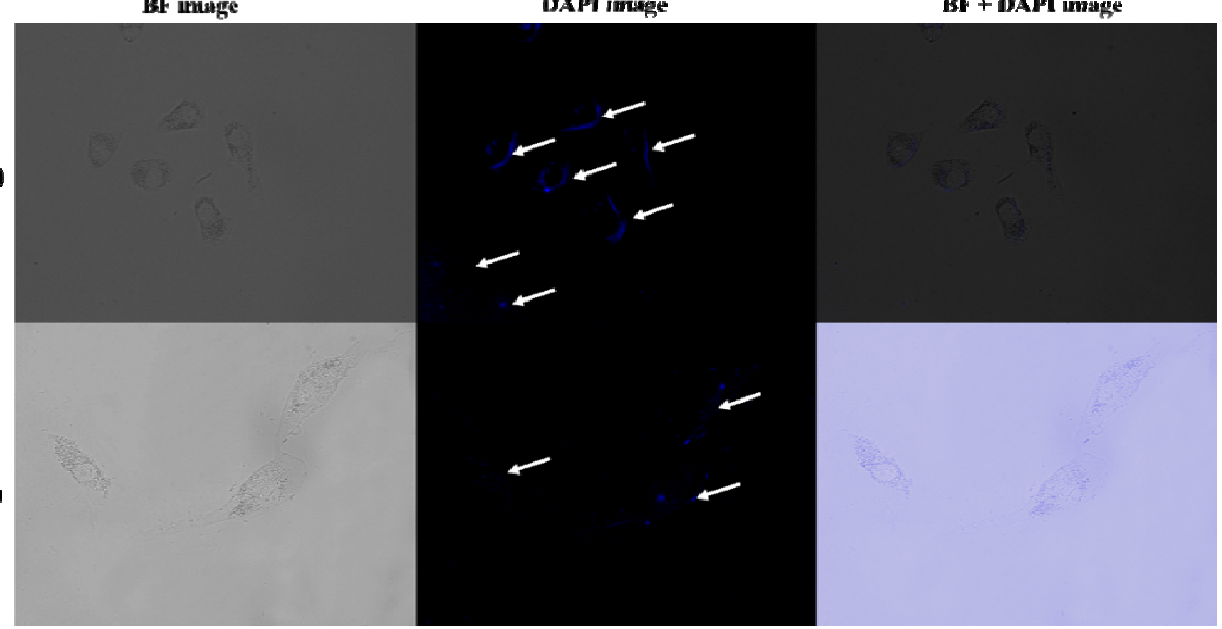

Figure S-14. Confocal laser scanning microscope (CLSM) images (40×) of A549 cells incubated with 2 (A) and 4 (B) carrying label-free ctDNA $(10 \mu \mathrm{g} / \mathrm{mL})$ for $0.5 \mathrm{~h}$. Concentrations $=10 \mu \mathrm{M}$

\section{IR spectra of compounds $1 \sim 4$ :}

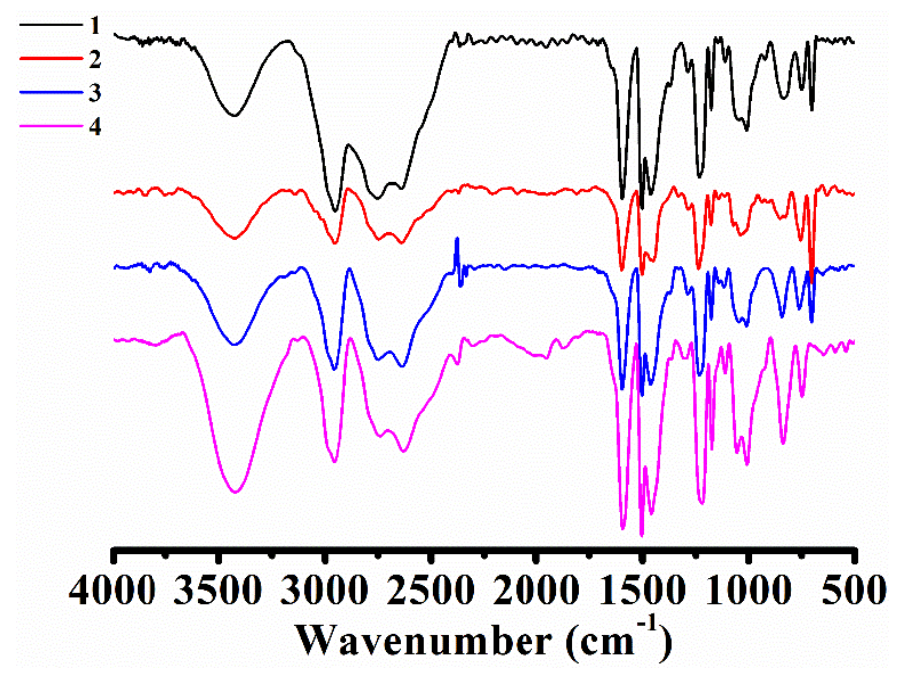

Figure S-15. FT-IR spectra of compounds 1, 2, 3 and 4. 
9. ${ }^{1} \mathrm{H},{ }^{13} \mathrm{C}-\mathrm{NMR}$ Spectra and HR-MS of compounds 1-4

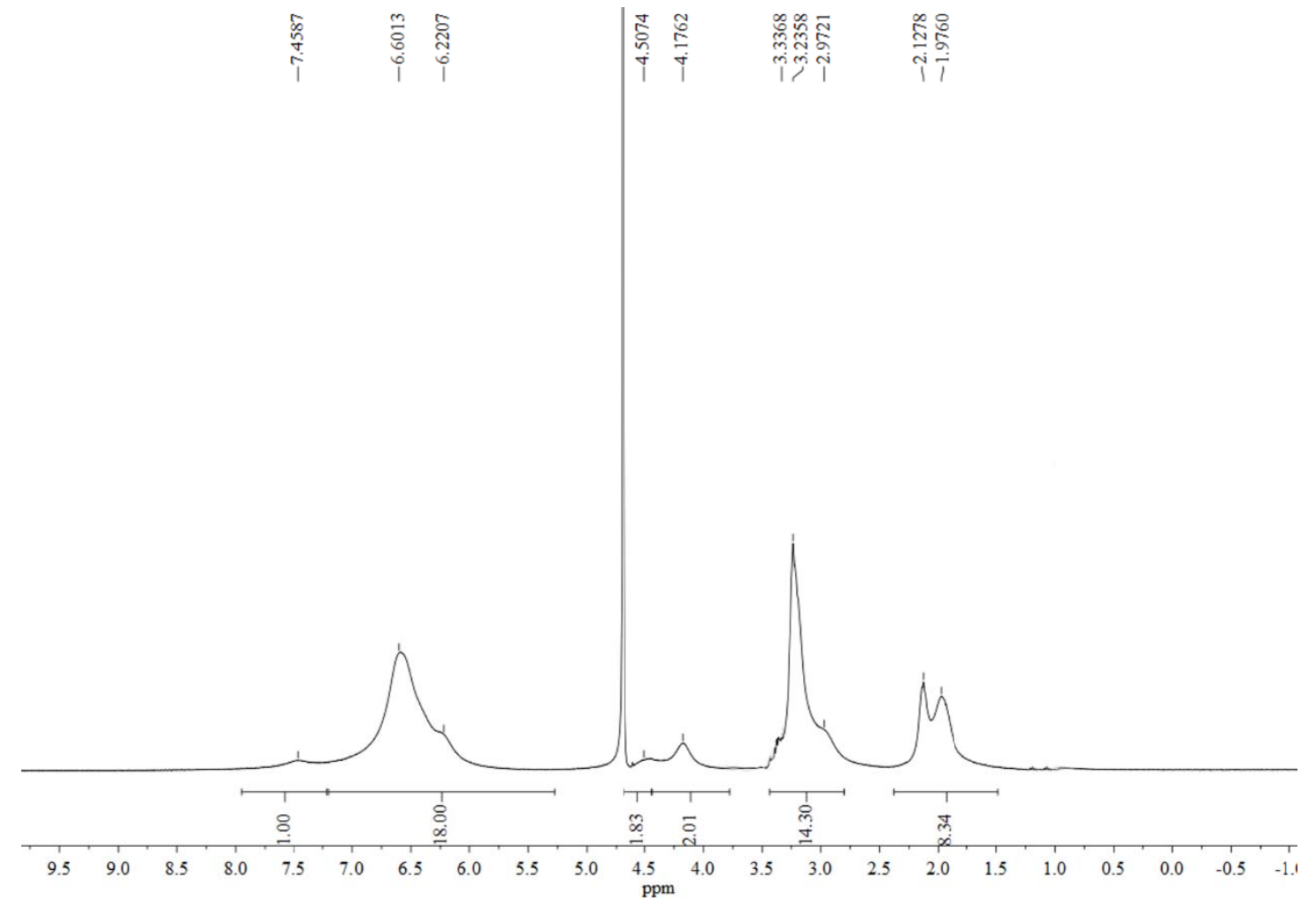

Figure S-16. ${ }^{1} \mathrm{H}$ NMR spectrum of $\mathbf{1}$ in $\mathrm{D}_{2} \mathrm{O}$.

IPEC:-1-13C

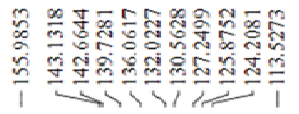

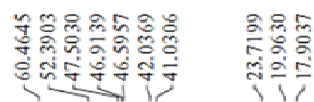

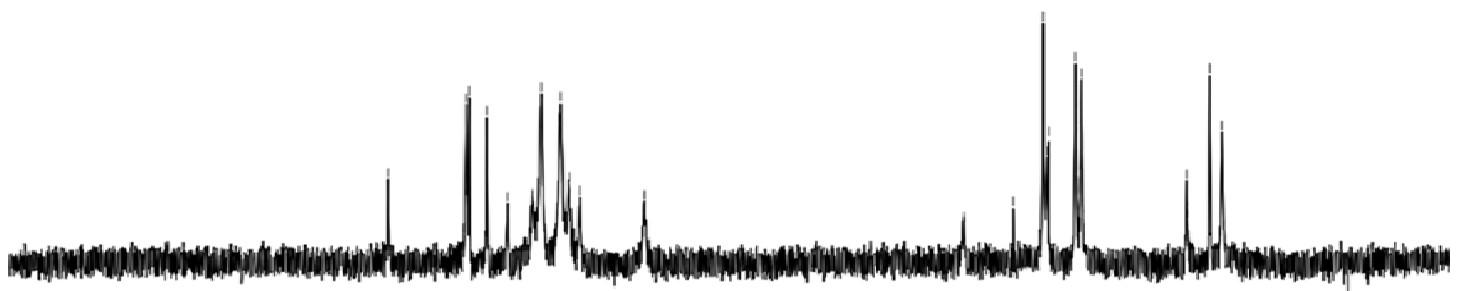

$\begin{array}{lllllll}210 & 200 & 190 & 180 & 170 & 160 & 150\end{array}$

Figure S-17. ${ }^{13} \mathrm{C}$ NMR spectrum of $\mathbf{1}$ in $\mathrm{D}_{2} \mathrm{O}$. 
Single Mass Analysis

Tolerance $=3.0 \mathrm{PPM}, \mathrm{DBE}: \min =-1.5, \max =100.0$
Element prediction: Off

Number of isotope peaks used for i-FIT $=2$

Monoisotopic Mass, Even Electron lons

1153 formula(e) evaluated with 4 results within limits (up to 100 best isotopic matches for each mass)
Elements Used:

$\begin{array}{llll}\text { C: } 0-50 & \text { H: } 0-60 & \text { N: } 0-10 & 0: 0-20\end{array}$

TPECN-1 $6(0.102)$

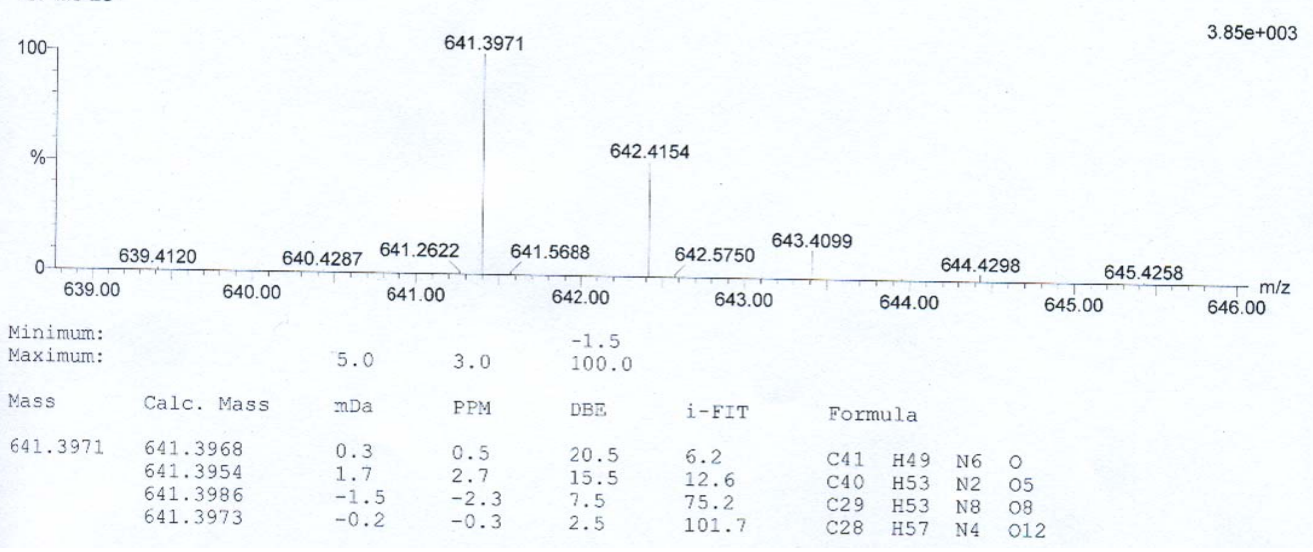

Figure S-18. HR-MS spectrum of $\mathbf{1}$.

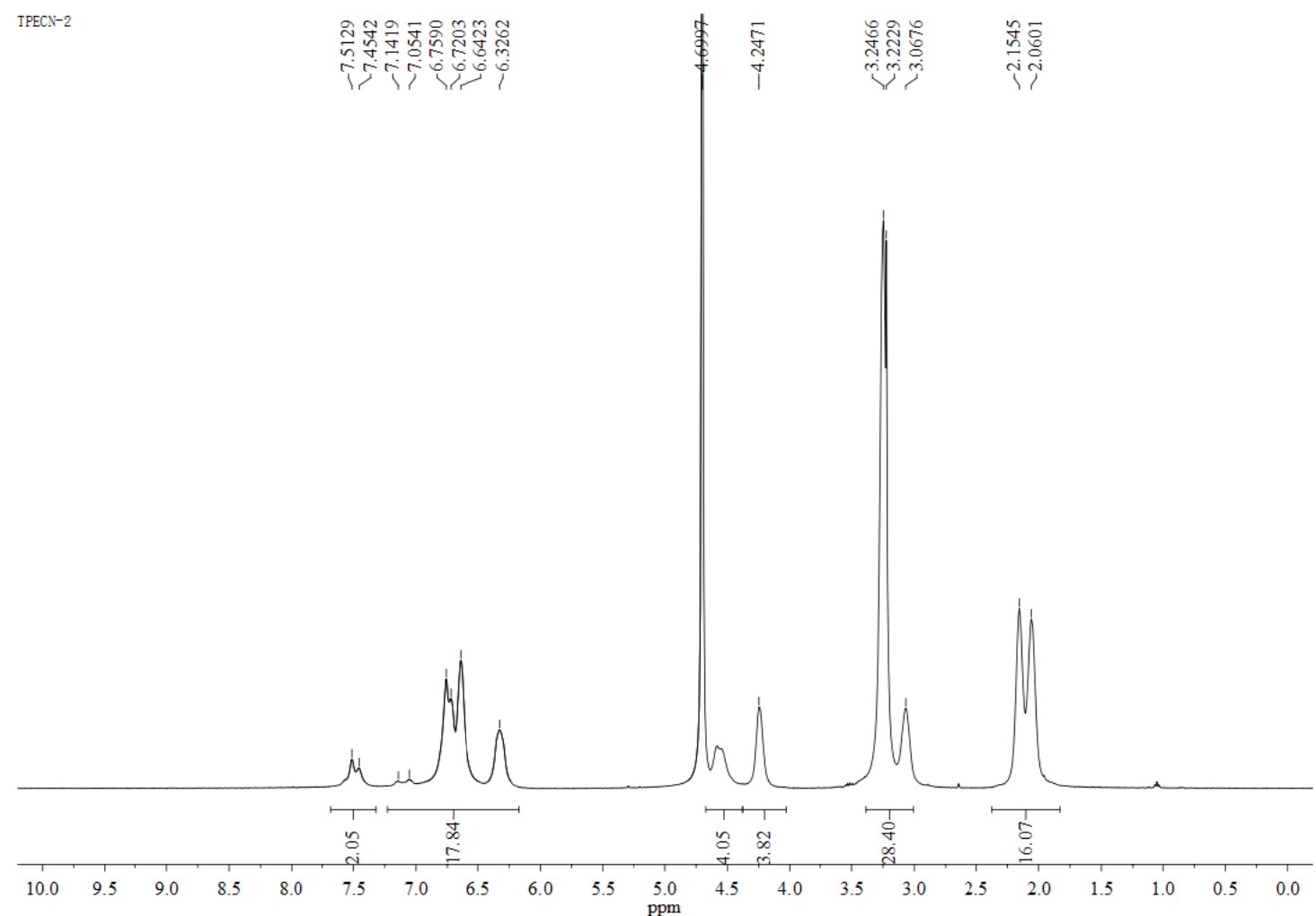

Figure S-19. ${ }^{1} \mathrm{H}$ NMR spectrum of 2 in $\mathrm{D}_{2} \mathrm{O}$. 

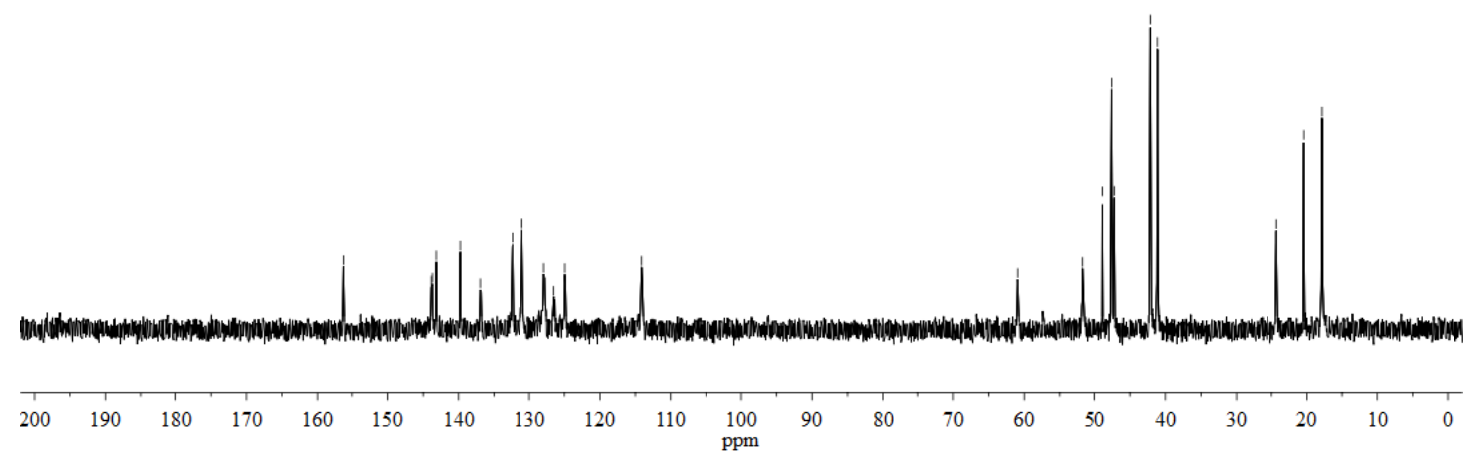

Figure S-20. ${ }^{13} \mathrm{C}$ NMR spectrum of 2 in $\mathrm{D}_{2} \mathrm{O}$.

\section{Elemental Composition Report}

Single Mass Analysis

Tolerance $=3.0$ PPM / DBE: $\min =-1.5, \max =100.0$

Element prediction: Off

Number of isotope peaks used for i-FIT $=2$

Monoisotopic Mass, Even Electron Ions

635 formula(e) evaluated with 1 results within limits (up to 100 best isotopic matches for each mass)

$\begin{array}{llll}\text { C: } 0-60 & \text { H: } 0-80 & \text { N: }: 0-15 & 0: 0-10\end{array}$

TPECN-2 38 (0.649)

TOF MS ES+

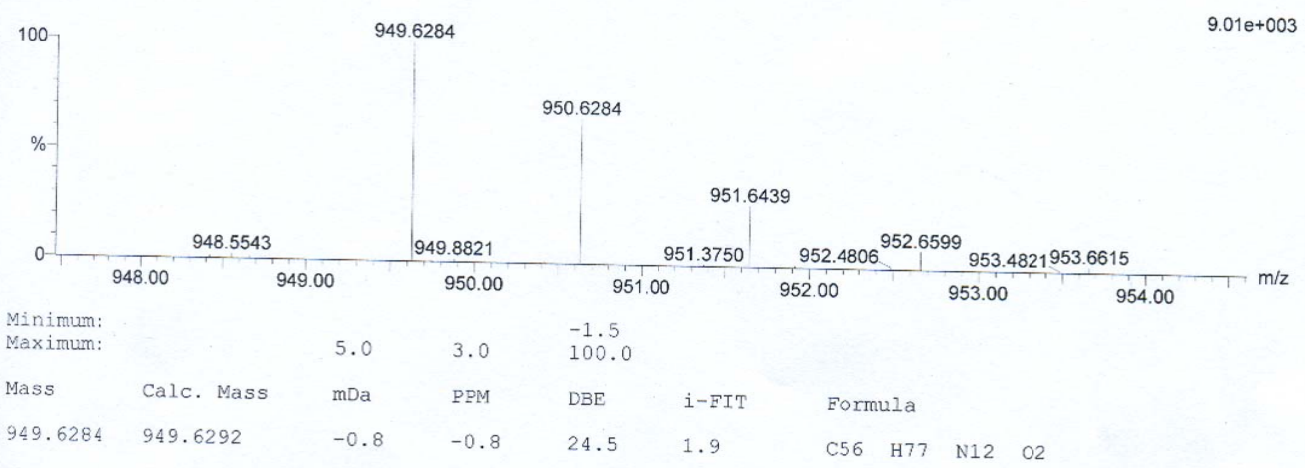

Figure S-21. HR-MS spectrum of 2. 


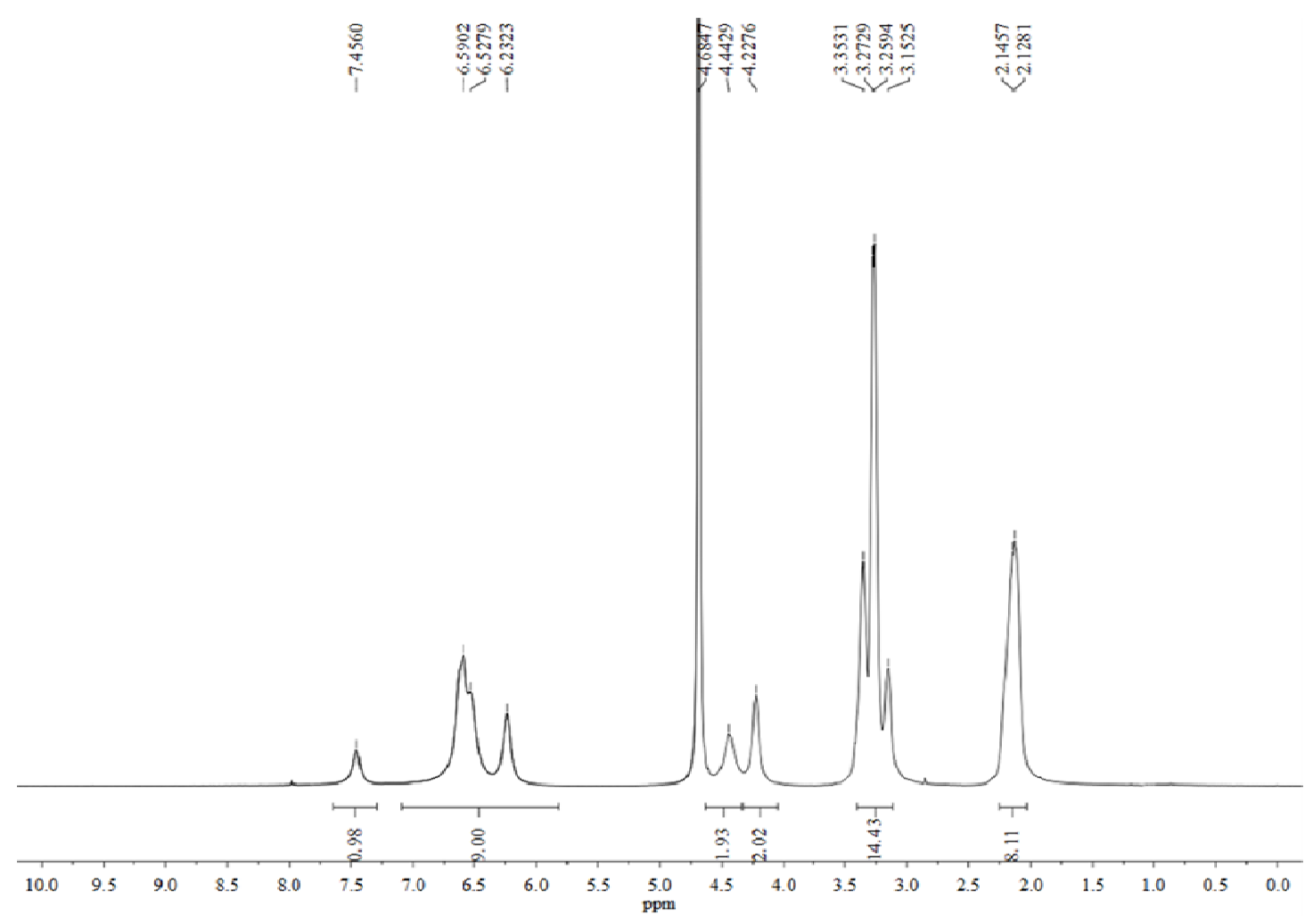

Figure S-22. ${ }^{1} \mathrm{H}$ NMR spectrum of $\mathbf{3}$ in $\mathrm{D}_{2} \mathrm{O}$.

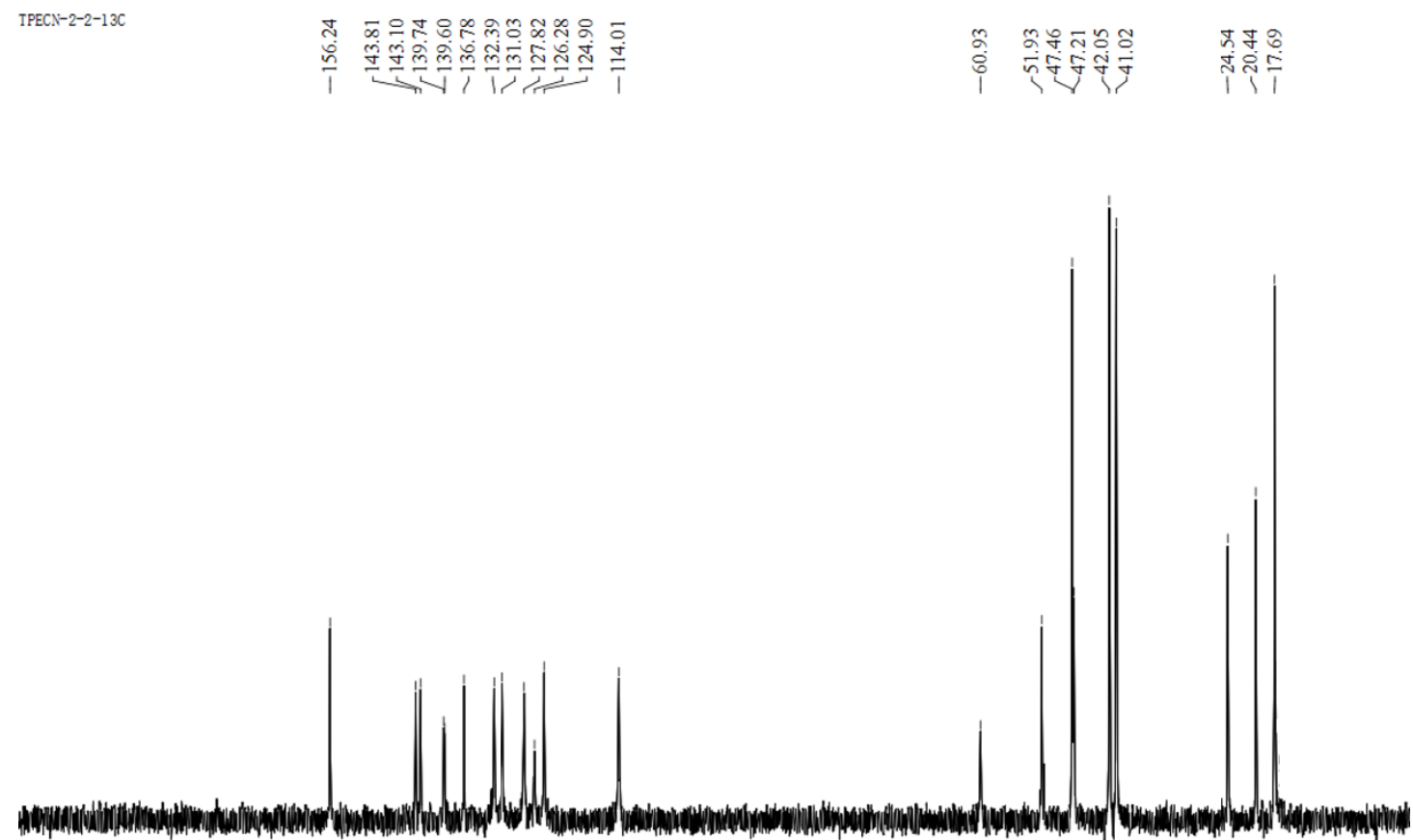

$\begin{array}{llllllllllllllllllllllll}1 & 200 & 190 & 180 & 170 & 160 & 150 & 140 & 130 & 120 & 110 & \begin{array}{l}100 \\ \mathrm{ppm}\end{array} & 90 & 80 & 70 & 60 & 50 & 40 & 30 & 20 & 10 & 0\end{array}$

Figure S-23. ${ }^{13} \mathrm{C}$ NMR spectrum of $\mathbf{3}$ in $\mathrm{D}_{2} \mathrm{O}$. 
Single Mass Analysis

Tolerance $=3.0$ PPM / DBE: $\min =-1.5, \max =100.0$
Element prediction: Off

Number of isotope peaks used for $\mathrm{i}-\mathrm{FIT}=2$

Monoisotopic Mass, Even Electron Ions

635 formula(e) evaluated with 1 results within limits (up to 100 best isotopic matches for each mass)

Elements Used:

C: $0-60 \quad \mathrm{H}: 0-8$

TPECN-3 $15(0.256)$

MS ES+

$100 \quad 949.628$

$1.40 \mathrm{e}+003$

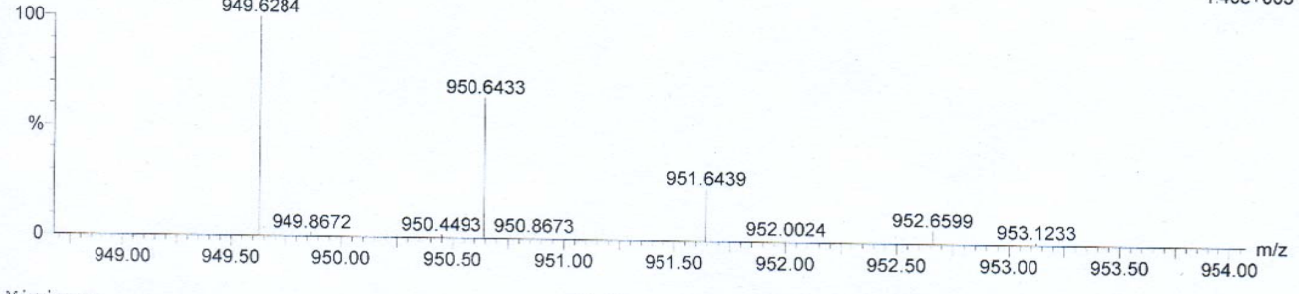

Minimum:

Maximum:

Mass Calc. Mass mDa PPM DBE

$5.0 \quad 3.0$

-1.5
100.0

$949.6284 \quad 949.6292$

$-0.8$

$-0.8$

Figure S-24. HR-MS spectrum of 3.

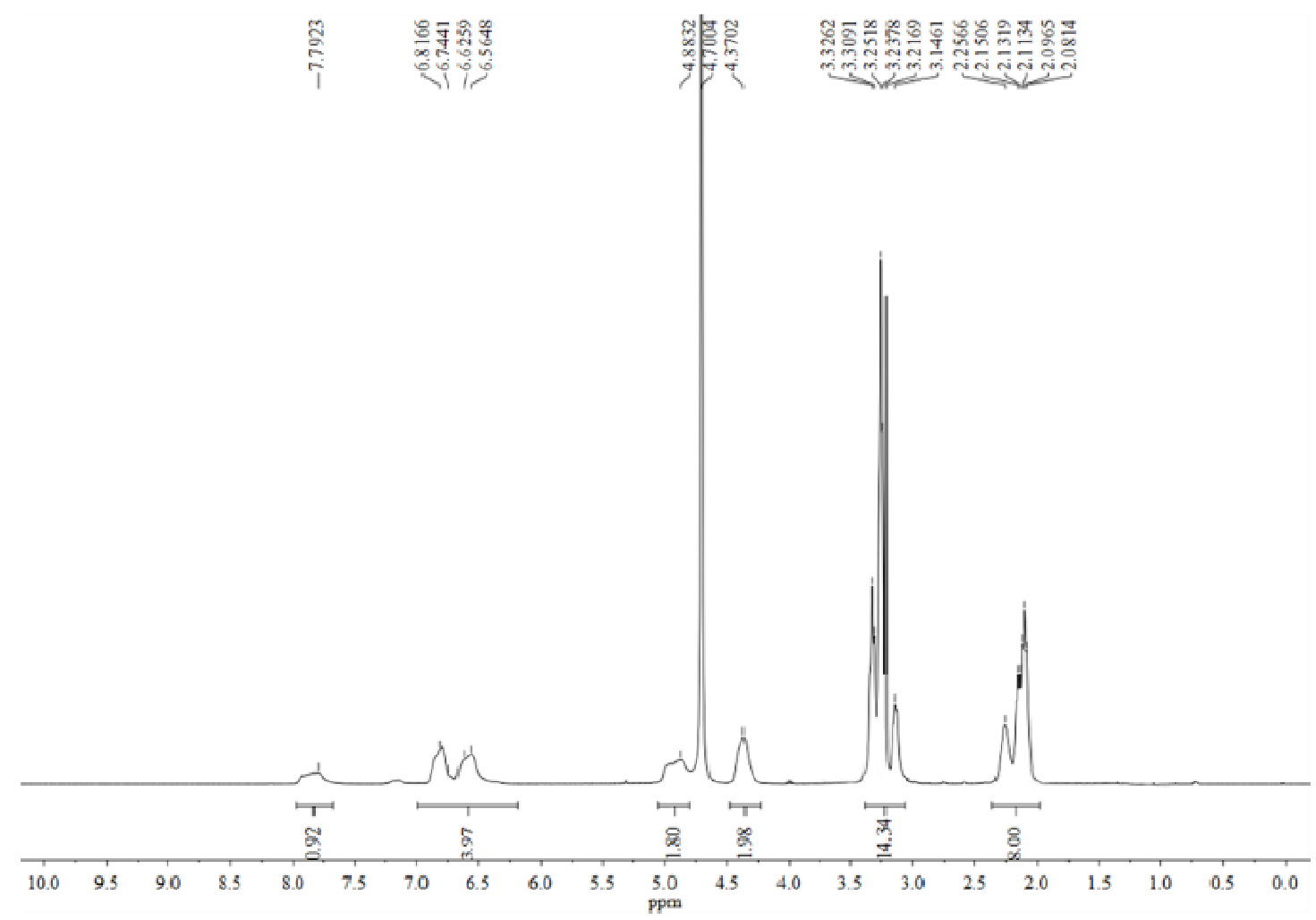

Figure S-25. ${ }^{1} \mathrm{H}$ NMR spectrum of 4 in $\mathrm{D}_{2} \mathrm{O}$. 

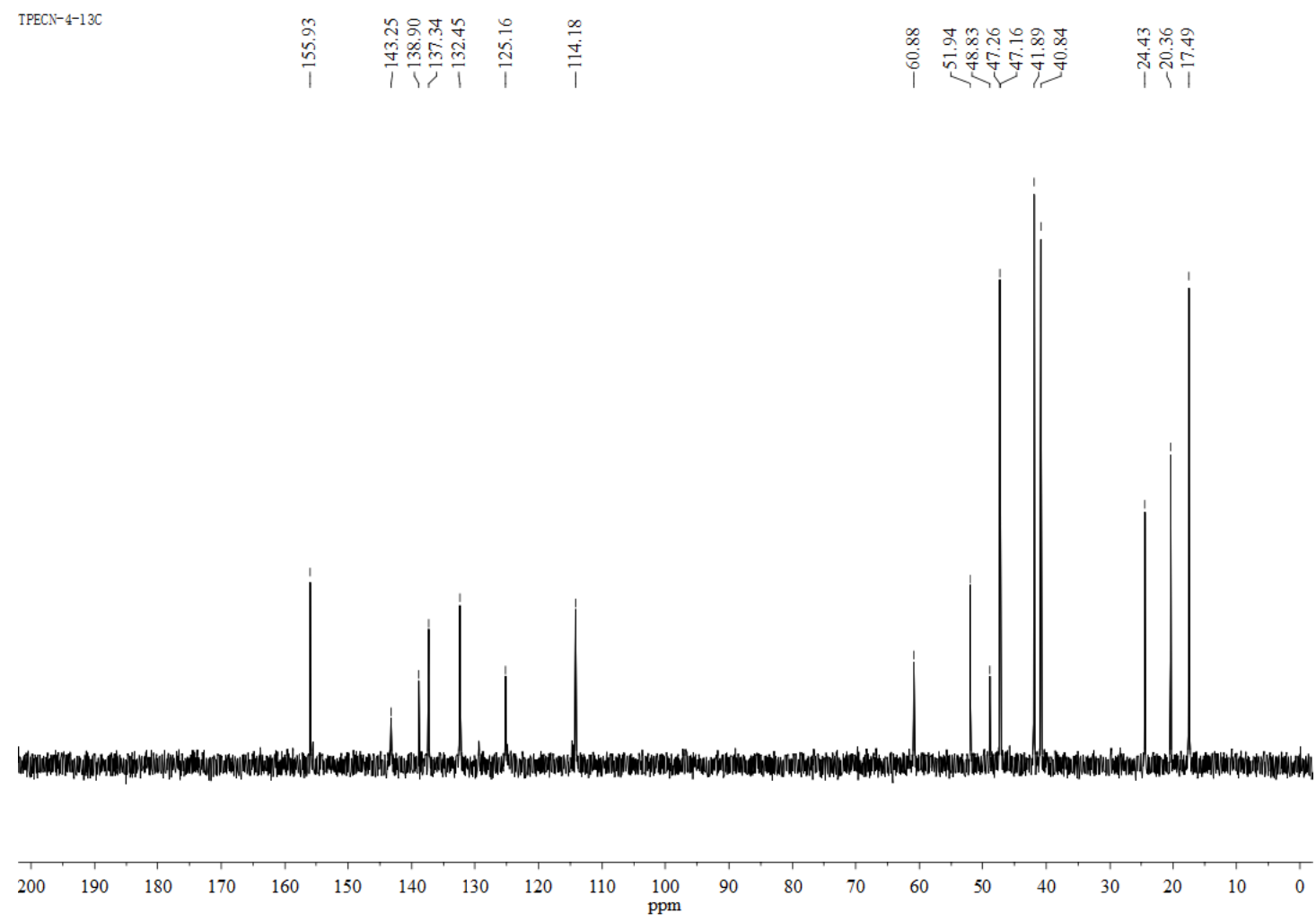

Figure S-26. ${ }^{13} \mathrm{C}$ NMR spectrum of 4 in $\mathrm{D}_{2} \mathrm{O}$.

Elemental Composition Report

Page 1

Single Mass Analysis

Tolerance $=3.0$ PPM / DBE: $\min =-1.5, \max =100.0$

Element prediction: Off

Number of isotope peaks used for i-FIT $=2$

Monoisotopic Mass, Even Electron Ions

1432 formula(e) evaluated with 10 results within limits (up to 100 best isotopic matches for each mass)

Elements Used:

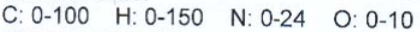

TPECN-4 $117(2.001)$
TOF MS ES+

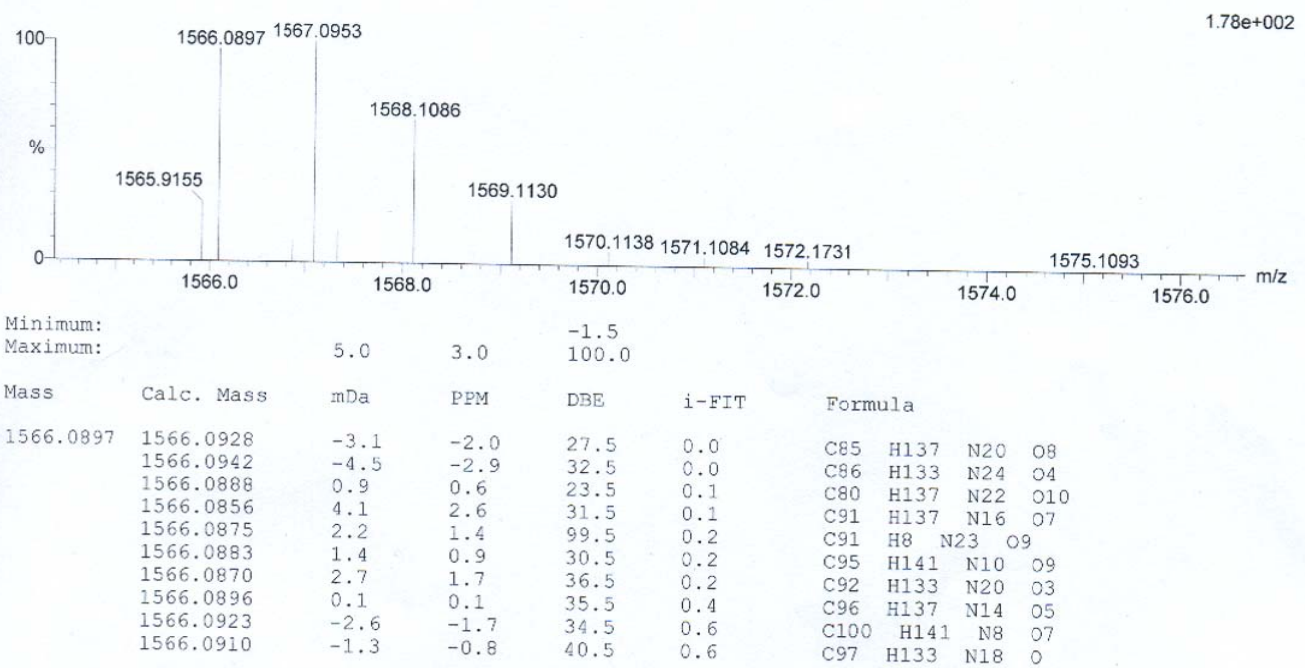

Figure S-27. HR-MS spectrum of 4. 


\section{References}

1) Li, Z. F.; Guo, Z. F.; Yan, H.; Lu, Z. L.; Wu, D. Y. Syntheses of [12] $\mathrm{aneN}_{3}$-Oligopeptide Conjugates as Effective DNA Condensation Agents. Bioorg. Med. Chem. 2012, 20, 2897-2904.

2) Yan, H.; Yue, P.; Li, Z.; Guo, Z.; Lu, Z. Syntheses of Bifunctional Molecules Containing [12] $\mathrm{aneN}_{3}$ and Carbazol Moieties as Effective DNA Condensation Agents. Sci. China Chem. 2013, 57, 296-306.

3) Yue, P.; Zhang, Y.; Guo, Z. F.; Cao, A. C.; Lu, Z. L.; Zhai, Y. G. Synthesis of Bifunctional Molecules Containing [12]aneN $\mathrm{N}_{3}$ and Coumarin Moieties as Effective DNA Condensation Agents and New Non-Viral Gene Vectors. Org. Biomol. Chem. 2015, 13, 4494-505.

4) Gao, Y. G.; Shi, Y. D.; Zhang, Y.; Hu, J.; Lu, Z. L.; He, L. A Naphthalimide-based [12]aneN ${ }_{3}$ Compound as an Effective and Real-time Fluorescence Tracking Non-Viral Gene Vector. Chem. Commun. 2015, 51, 16695-16698. 